Geopolítica(s) Revista de estudios sobre espacio y poder ISSN: 2172-3958

http://dx.doi.org/10.5209/rev_GEOP.2016.v7.n1.52949

\title{
Massey y Soja: dos cimientos de la geografía política crítica
}

Consejo de Redacción

Cómo citar: Consejo de Redacción (2016) "Massey y Soja: dos cimientos de la geografía política crítica”. Geopolítica(s). Revista de estudios sobre espacio y poder, vol. 7, núm. 1, 11.

No es habitual en esta revista hacer necrológicas ni comentarios biográficos, pero hacemos una excepción en este caso por las tremendas pérdidas que la geografía política ha sufrido en los últimos meses. Tras la muerte de Edward Soja el 2 de Noviembre de 2015, el 11 de Marzo de 2016 nos sorprendía el deceso de Doreen Massey. Ambos autores han sido decisivos en la resurrección de la geografía política en las últimas décadas, desde las primeras reflexiones de Soja sobre la territorialidad hasta los últimos trabajos de Massey sobre el espacio, centrándose uno en las ciudades (en Los Angeles, particularmente) y explorando la otra las vinculaciones del lugar con lo global. Ambos han utilizado autores y categorías marxistas en sus trabajos, y ambos han tenido una vida políticamente comprometida (en particular Massey). En definitiva, han sido dos cimientos de la geografía política crítica en un sentido lato.

Más allá de los tópicos sobre lo irreparable de las pérdidas, en Geopolítica(s) queremos homenajear a ambos y recordar a todos las deudas, ya impagables, que tenemos con uno y otra. A tal fin, hemos seleccionado cuatro obituarios (dos de cada uno) que han aparecido en diversos medios: el primero de Edward Soja corresponde a las emocionadas palabras que pronunció Olivier Kramsch, miembro de nuestro Consejo Asesor, en la reunión anual de la Association of American Geographers (hemos decidido publicarlo en el inglés original para mantener los matices); el segundo es el obituario formal de Soja que apareció en la página web de la AAG; el tercero es una poética y sentida despedida de Doreen Massey por parte de Gillian Rose (en inglés por los mismos motivos que el primero); y el cuarto es un obituario de Massey con un magnífico análisis de su obra por David Featherstone. 